\title{
UTILIZAÇÃO DA COMPARTIMENTAÇÃO FISIOGRÁFICA COMO SUBSÍDIO NA INDICAÇÃO DE ÁREAS SUSCEPTÍVEIS A MOVIMENTOS DE MASSA: ESTUDO DE CASO EM CARAGUATATUBA E SÃO SEBASTIÃO (SP)
}

\author{
Claudia Vanessa dos Santos Corrêa(a), Fábio Augusto Gomes Vieira Reis(b), Lucília Carmo \\ Giordano(c), Camila Jardinetti Chaves(d), Ana Maria Carrascosa do Amaral(e) \\ (a) Instituto de Geociências e Ciências Exatas, Universidade Estadual Paulista "Júlio de Mesquita Filho", \\ claudiageobrax@yahoo.com.br \\ (b) Instituto de Geociências e Ciências Exatas, Universidade Estadual Paulista "Júlio de Mesquita Filho", \\ fabioreis@rc.unesp.br \\ (c) Instituto de Geociências e Ciências Exatas, Universidade Estadual Paulista “Júlio de Mesquita Filho", \\ lcg@ecogeologia.com.br \\ (d) Instituto de Geociências e Ciências Exatas, Universidade Estadual Paulista "Júlio de Mesquita Filho", \\ camila.j.chaves@gmail.com \\ (e) Instituto de Geociências e Ciências Exatas, Universidade Estadual Paulista "Júlio de Mesquita Filho", \\ ana.eng.ambiental@hotmail.com
}

\section{Eixo: GEOGRAFIA FÍSICA E DESASTRES NATURAIS}

\begin{abstract}
Resumo/
O objetivo deste trabalho foi de realizar a compartimentação fisiográfica das bacias hidrográficas Juqueriquerê, Santo Antônio e São Francisco, inseridas nos municípios de Caraguatatuba e São Sebastião (SP), em escala 1:50.000, com finalidade de identificar os locais com maior vulnerabilidade à ocorrência de movimentos de massa, com subsídio de bases cartográficas em escala 1:50.000 (IBGE), mapas geológicos em escala 1:50.000 (IG/ CPRM) e ortofotos com resolução 1:10.000 (EMPLASA), além de identificação de cicatrizes de escorregamento. Foram delimitadas unidades fisiográficas nas planícies fluviais e flúvio-marinhas; nos locais com depósitos de colúvio e de tálus, nos granitoides em morros isolados, nos granitoides e gnaisses-migmatitos associados às médias e baixas encostas de serra e nas áreas de topo com predominância de granitoides e a gnaisses migmatitos. Observou-se que as unidades fisiográficas localizadas na região serrana possuem maior potencialidade à ocorrência de processos de movimentos de massa devido aos seus valores de densidade textural.
\end{abstract}

Palavras chave: Serra do Mar, Planície Costeira, Movimentos de massa, Cicatrizes de escorregamento

\section{Introdução}

Os desastres naturais constituem hoje uns dos grandes problemas socioeconômicos mundiais. Dentre os fenômenos que mais se destacam, podemos citar os terremotos, inundações e movimentos de massa. Estes, por sua vez, são objeto de interesse de grande parte de pesquisadores e planejadores e/ou administradores públicos, pois podem atingir áreas com importantes infraestruturas para um país, como oleodutos, 
gasodutos, aquedutos, estradas, linhas de transmissão, além de complexos industriais e centros urbanos, tendo como consequência mais grave a perda de vidas humanas (GOMES, 2006).

De acordo com a ONU (1993), um dos fenômenos que mais causam prejuízos financeiros e mortes no mundo são os movimentos de massa. Estes fenômenos naturais são importantes processos de modelamento do relevo e têm sua ocorrência ligada às encostas. Nas cidades estes assumem, em geral, proporções catastróficas, uma vez que são feitas diversas modificações na paisagem natural que acabam se relacionando com os fatores naturais propiciando a deflagração destes processos (BRUNSDEN; PRIOR, 1984; SILVA-FILHO, 1992; MONTGOMERY, 1994; FERNANDES; AMARAL, 1996; LARSEN; TORRES-SÁNCHEZ, 1998; ZERKAL; ZERKAL, 2004). Nesse contexto, com o aumento populacional das últimas décadas, em sua maioria sem planejamento adequado, a ocorrência de processos de dinâmica superficial vem aumentando significativamente. A ocupação de encostas íngremes e de margens de córregos sem obedecer a critérios técnicos é um fator que acelera os movimentos de massa, e consequentemente, pode aumentar os danos provocados (WRIGHT; KRONE, 1990).

Segundo dados do Centro de Pesquisa de Epidemiologia em Desastres (CRED) da Organização Mundial da Saúde (OMS), o Brasil está entre os dez países mais afetados por desastres no mundo (EM-DAT, 2008). Neste contexto, Augusto Filho (1992) e Gramani (2001) elaboraram o levantamento dos acidentes mais importantes envolvendo movimentos de massa no Brasil. As áreas mais susceptíveis a ocorrência desses processos no Brasil são as áreas situadas no sopé da Serra do Mar, da Serra da Mantiqueira e da Serra Geral, estendendo-se desde a região Sul até a região Norte. No município de Caraguatatuba, no Estado de São Paulo, em 1967 ocorreu um dos mais expressivos movimentos de massa registrados no estado e no Brasil, ocasionado por fortes chuvas que caíram sobre a região. Estima-se que mais de 30 mil árvores desceram as encostas da Serra do Mar e atingiram as porções baixas do relevo. Cerca de 400 moradias foram total ou parcialmente destruídas e, oficialmente, foram contabilizados 120 mortos e milhares de pessoas desabrigadas (GOMES et al., 2008).

A Serra do Mar destaca-se por ser uma área onde existem importantes rodovias que ligam o planalto ao litoral, estradas de ferro, dutovias e indústrias. Cerca de $90 \%$ dos produtos de todo o Estado de São Paulo são escoados pelo Porto de Santos, pelas Rodovias Imigrantes e Anhanguera, que cortam a Serra do Mar. Freitas et al. (1990) fizeram um cadastro das situações de risco no trecho paulista da Serra do Mar, focando obras lineares como agentes indutores de processos de instabilização do terreno. Os autores concluíram que é importante controlar as situações de risco associadas a este tipo de empreendimento, uma vez que podem ocasionar, além de processos erosivos, corridas de massa e escorregamentos. 
Na tentativa de identificar os locais com maior vulnerabilidade à ocorrência desses processos, destaca-se a técnica de compartimentação fisiográfica, que segundo Cardoso et al. (2009) e Silva et al. (2010) permite a síntese das informações do meio físico, já que a partir de critérios estabelecidos, propriedades similares ou idênticas são identificadas no interior de áreas com características homogêneas. Paula et al. (2008) salienta que a vantagem da aplicação deste método consiste na geração de um único produto cartográfico seccionado em várias 'unidades da paisagem', que resumem características de relevo, solo, geologia, vegetação, uso da terra e socioeconômicas. Ademais, este método utiliza-se de técnicas de sensoriamento remoto e geoprocessamento para delimitar unidades fisiográficas, que por sua vez fornecem subsídios para o levantamento atualizado de recursos ambientais (relevo, solos, minérios e água) nas intervenções no meio físico, onde é vital que as tomadas de decisões garantam a sua viabilidade e a melhor relação entre funcionalidade e custo/benefício (CORRÊA, 2013). Deste levantamento resultam mapas temáticos básicos (uso e cobertura do solo, geomorfologia e declividade e outros) contendo as informações mais relevantes ao problema, de modo que este pode ser diagnosticado e modelado, orientando a integração dos dados em mapas-síntese, cartogramas, tabelas e quadros, que subsidiam o processo de planejamento e os prognósticos que norteiam a tomada de decisões (PENIDO et al., 1998).

Assim, considerando essas premissas iniciais, o objetivo deste trabalho é de apresentar e discutir a compartimentação fisiográfica na região de Caraguatatuba e São Sebastião, Estado de São Paulo, em escala 1:50.000, cuja finalidade é indicar quais são os locais com maior susceptibilidade à ocorrência de movimentos de massa.

\section{Caracterização da área de estudo}

A área de estudo compreende às bacias hidrográficas do Rio Santo Antônio, do Rio Juqueriquerê e do Rio São Francisco, localizadas nos municípios de Caraguatatuba e São Sebastião (SP), no contexto geomorfológico do Planalto Atlântico e da Província Costeira (Figura 1). A Província Costeira é dividida por Almeida (1964) em Serranias Costeiras e Zona da Baixada Litorânea. As planícies possuem ocorrência restrita distribuídas por um litoral bastante recortado, onde são frequentes as enseadas e praias. A costa é abruptamente interceptada pela borda oriental do Planalto Atlântico com ocorrência de pontões rochosos perpendiculares à direção geral desta estrutura, os quais favorecem a formação de baías.

Segundo o mesmo autor, a ação dos movimentos neotectônicos, representada pelos movimentos de blocos de falhas, é responsável pelo desenvolvimento de rifts e soerguimento da Serra do Mar e Mantiqueira. Esses movimentos ocorreram basicamente ao longo de antigas linhas de fraqueza do Pré-cambriano, com direção predominante leste-nordeste determinando a linha de costa atual. Esta área encontra-se totalmente 

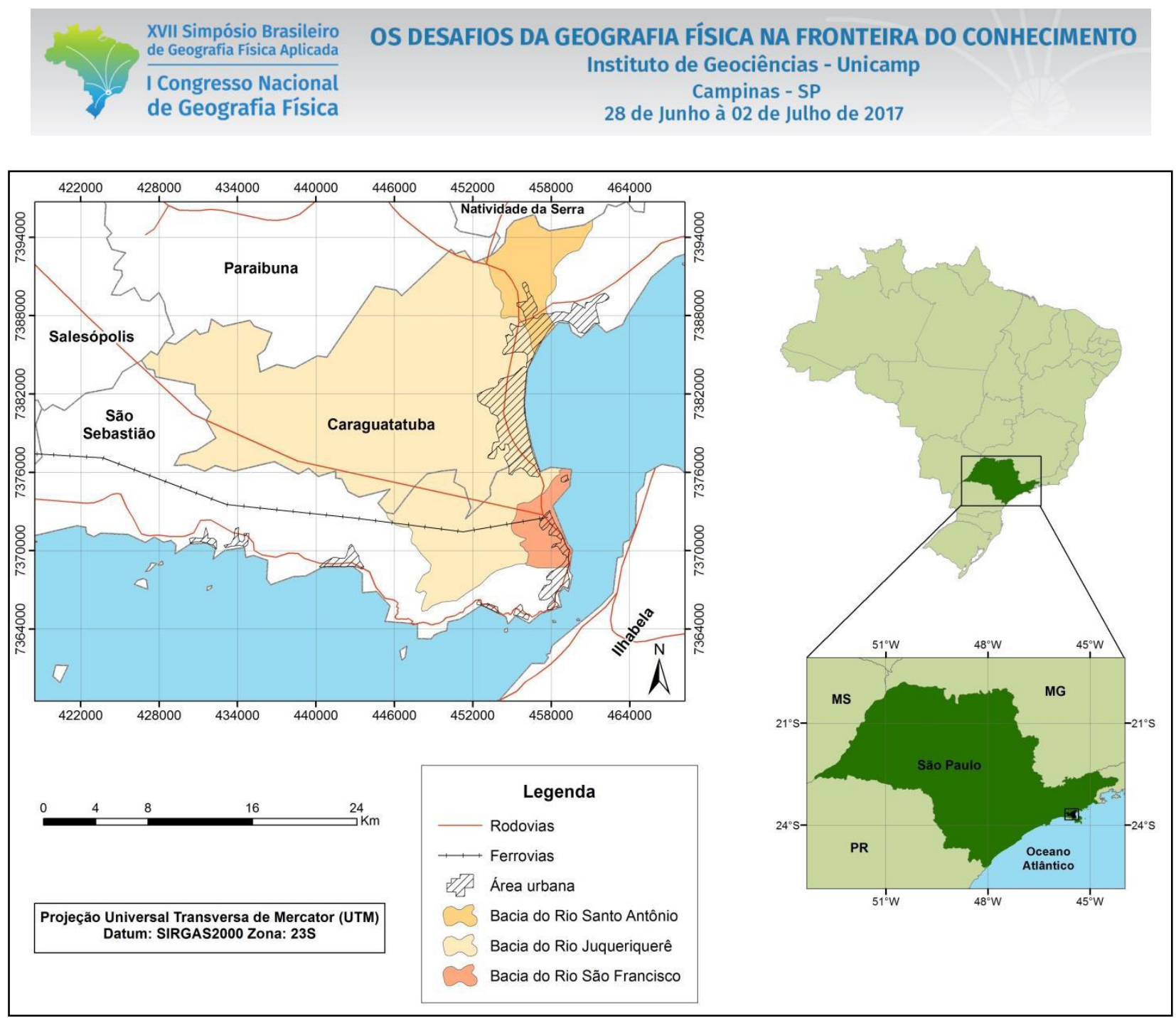

inserida no Embasamento Cristalino em trecho do cinturão de cisalhamento transcorrente Paraíba do Sul. Com relação à litologia da região serrana, destaca-se a ocorrência de rochas polimetamórficas de idade arqueana (migmatitos, gnaisses, granito-gnaisses, biotita gnaisses), granitóides foliados do proterozóico superior, rochas cataclásticas cambro-ordivicianas e intrusões básicas localizadas, de idade mesozóica (geralmente na forma de diques).

Figura 1 - Localização da área de estudo

\section{Materiais e métodos}

Para a elaboração do presente trabalho foram utilizados os seguintes materiais: cartas topográficas em escala 1:50.000 do IBGE das folhas Caraguatatuba (SF-23-Y-D-VI-1), Pico do Papagaio (SF-23-Y-D-V2), Maresias (SF-23-Y-D-V-4) e São Sebastião (SF-23-Y-D-VI-3) (IBGE, 1973; 1974a; 1974b; 1975), 


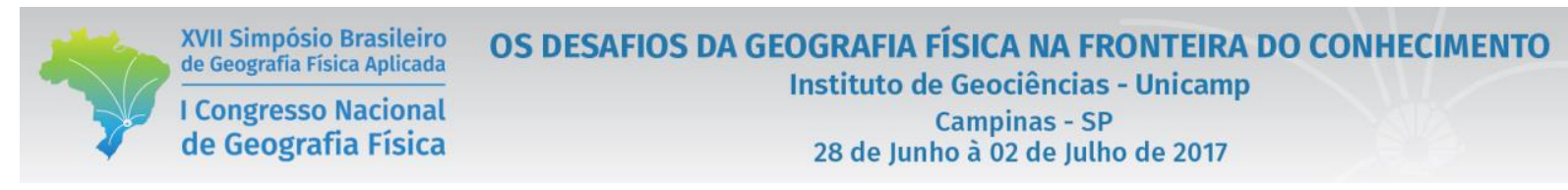

mapa geológico em escala 1:50.000 das folhas Caraguatatuba e Pico do Papagaio (CPRM, 1982; 1991) e São Sebastião (IG, 1996), além de ortofotos em escala 1:10.000 da Emplasa.

No que tange ao método, primeiramente foram gerados mapas de declividade, hipsometria e hidrografia da área de estudo, selecionando-se como dados de entrada as curvas de nível vetorizadas das cartas topográficas supracitadas, que foram submetidas a processos de geoprocessamento na plataforma ArcGis 10.2.2.

Para a realização da compartimentação fisiográfica da área de estudo, sua elaboração seguiu as recomendações da interpretação pelo método lógico (GUY, 1966; SOARES; FIORI, 1976). Neste método os estudos de textura, forma e estrutura das feições seguem as etapas de fotoleitura, fotoanálise e fotointerpretação. Segundo Soares e Fiori (op. cit.), a etapa de fotoleitura compreende o reconhecimento dos elementos de textura de interesse na imagem; a fotoanálise, por sua vez, faz a associação e ordenação das partes da imagem analisada e a fotointerpretação trata da análise da imagem visando à descoberta e avaliação, por métodos indutivos, dedutivos e comparativos do significado, função e relação dos objetos correspondentes às imagens. No caso do presente trabalho foram utilizadas imagens de sensoriamento orbitais, portanto as colocações de Veneziani e Anjos (1982) e Soares et al. (1978) foram necessárias.

A caracterização geológico-geotécnica foi baseada nos resultados da interpretação das imagens pelas etapas anteriores e pelo trabalho de campo. Segundo Oliveira (2009), a obtenção de dados geotécnicos a partir de dados de sensoriamento remoto é feita a partir da correlação entre as propriedades texturais e espectrais da imagem e propriedades e/ou características do meio físico de interesse geotécnico. De acordo com Vedovello (2000), o princípio considerado para a correlação é o de que a textura na imagem reflete as características e propriedades dos materiais que são imageados. As análises realizadas nessa fase seguiram as orientações dos itens "Aplicações", "Análise de densidade textural" e "Análise das formas e características do relevo" propostos por Zaine (2011).

Ademais, para verificar se ocorrem movimentos de massa na respectiva área de estudo, foram realizadas atividades de fotointerpretação em ortofotos digitais datas de 2011 para a identificação de cicatrizes de escorregamento.

\section{Resultados e discussões}

\subsection{Compartimentação fisiográfica}


A partir da etapa de compartimentação fisiográfica, foram identificadas na área de estudo 17 unidades fisiográficas distribuídas ao longo da Província Costeira e do Planalto Atlântico, com diferentes contextos geológicos (Figura 2).

As unidades fisiográficas 2, 4, 5, 6, 7, 9 possuem alta densidade textural, e, portanto, alta densidade de drenagem e de relevo. Nestas, de maneira geral, os vales são fechados, a amplitude local é média a alta, bem como os valores de declividade, as encostas variam de convexas a retilíneas e a forma dos topos varia de arredondada a angulosa. Em relação às características geológico-geotécnicas, nestas unidades a permeabilidade intergranular varia de média para baixa, a relação escoamento superficial pela infiltração é média, bem como a profundidade do manto de alteração e o topo rochoso varia de raso a sub aflorante. Nestes locais foram encontradas inúmeras evidências de ocorrência de movimentos de massa, através da identificação visual e mapeamento das cicatrizes (Figura 3). Nesse sentido, a etapa de fotointerpretação revelou que para estas unidades a potencialidade a movimentos de massa pode variar de média a alta, devido à morfologia das bacias hidrográficas e a densidade de drenagem. Cabe ressaltar que movimentos de massa desta classe desenvolvem-se principalmente ao longo dos canais de drenagem de primeira à terceira ordem, com valores de inclinação do talvegue elevados. Nesse sentido, apesar de possuir baixos valores de densidade textural, a unidade fisiográfica 1, denominada de planícies aluviais restritas, é caracterizada como uma região com alta probabilidade de ocorrência de corridas de massa, devido à inclinação do talvegue e sua inserção em bacias com formato mais circular e fechado, possibilitando a hiperconcentração dos fluxos e favorecendo o escoamento superficial rápido de detritos. As unidades 2,4 , 5, 6, 7 e 9 abrangem principalmente morfologias de relevo serrano a escarpado e litologias que variam de gnaisses-migmatítiticas a granitos. 


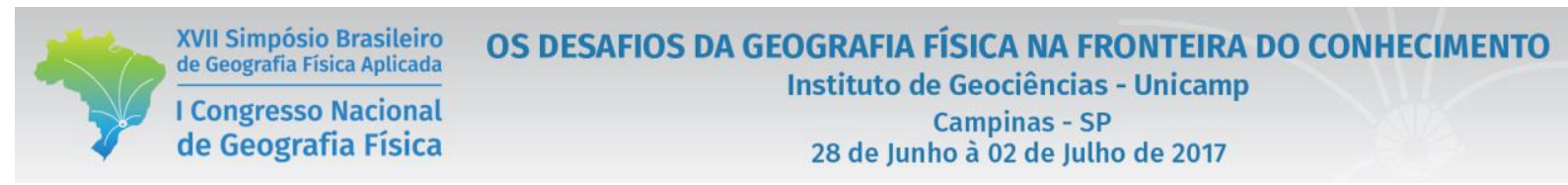

Compartimentação fisiográfica preliminar das bacias hidrográficas do Rio Santo Antônio, do Rio Juqueriquerê e do Rio São Francisco, municípios de Caraguatatuba e São Sebastião (SP)
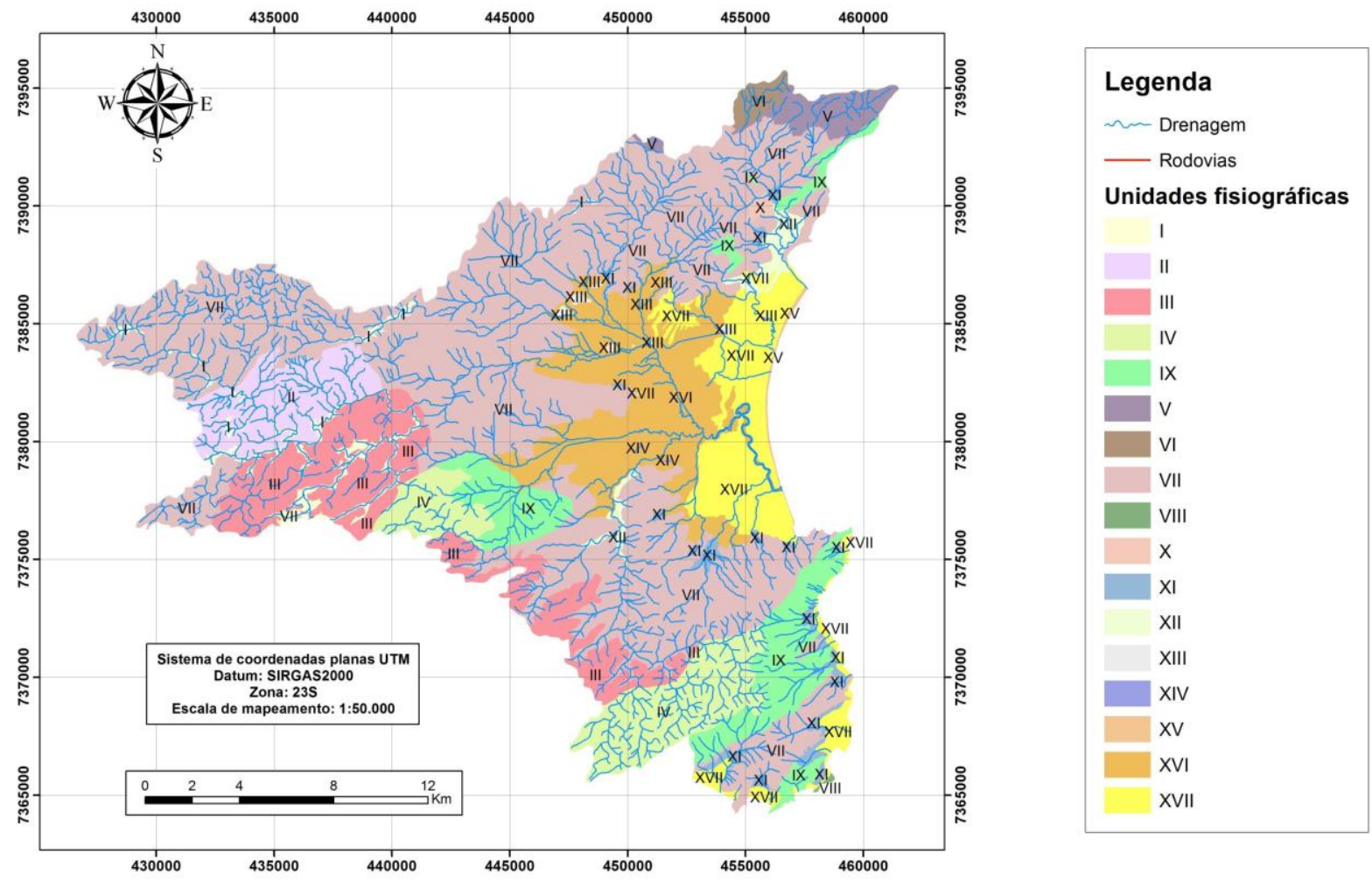

Figura 2 - Mapa de compartimentação fisiográfica

As unidades 3, 10 e 11 possuem médios valores de densidade textural. Nesse sentido, observa-se nestes locais médias amplitudes locais, baixos a médios valores de declividade e forma de encostas que pode variar de côncava a convexa. Ademais, os topos são, em sua maioria, arredondados e podem ser encontrados vales abertos a fechados. Em relação às características geológico-geotécnicas, o manto de alteração nestes locais é médio, a profundidade do topo rochoso é intermediária e o potencial a escorregamentos e corridas de massa varia de baixo a médio. Cabe destacar que a unidade 11 é representada pelas rampas de colúvios e tálus e sua potencialidade a corridas de massa é alta.

As unidades com baixa densidade textural estão concentradas principalmente na Província Costeira e sua principal característica é a baixa densidade de drenagem e ausência de estruturas geológicas orientadas. Nesse sentido, as unidades 8,12,13,14, 15, 16 e 17, indicadas por modelados "planície costeira", "planície aluvial", "praial" e "colinas isoladas" possuem baixa probabilidade à ocorrência de movimentos de massa em seu interior. 


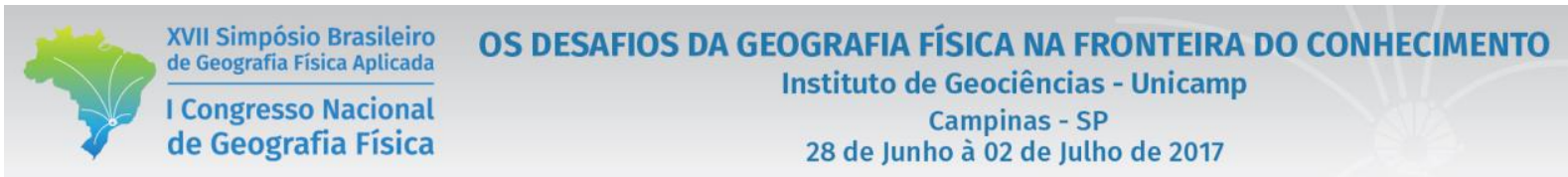

\subsection{Cicatrizes de escorregamento}

Foram registradas 406 cicatrizes de escorregamento na área em questão, conforme indica a Figura 3.

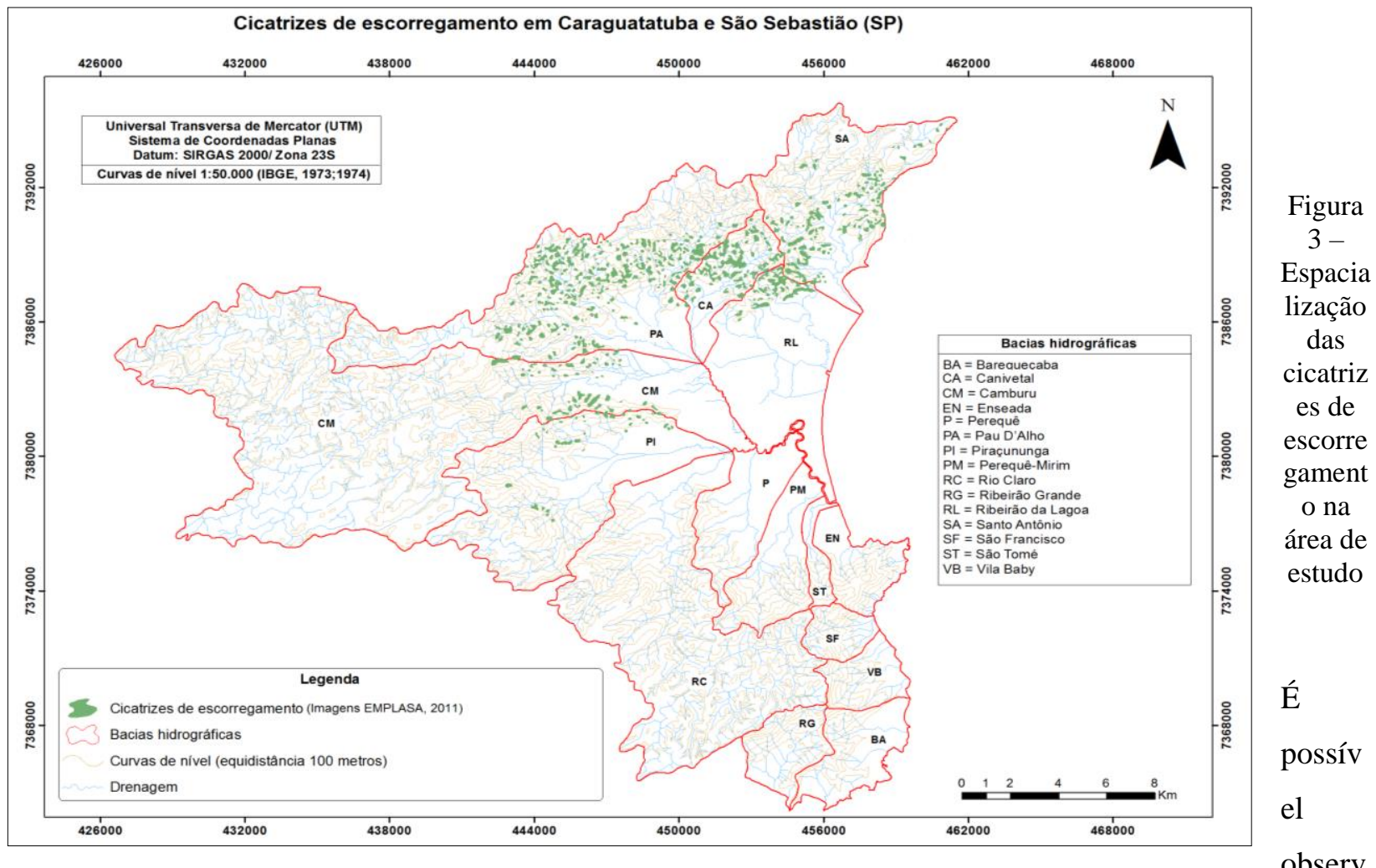

ar que os locais mais atingidos por movimentos de massa estão representados principalmente pela unidade 
fisiográfica 7, cuja característica geológica-geotécnica está condicionada à deflagração destes processos. Entretanto, cicatrizes também são identificadas em outras unidades, tais como "13" e "11". A unidade 11, conforme supracitado, pode apresentar processos de movimentos de massa, devido à presença de rampas de tálus e colúvio; porém, a unidade 13 situa-se em locais com baixa densidade de relevo. Atividades de retro-análise realizadas concomitantemente a este trabalho relevaram que a ocorrência de um grande evento no local, datado de 1967, que foi deflagrado por intensas chuvas na região. Neste, principalmente os canais de primeira ordem foram atingidos pelos escorregamentos generalizados, que rapidamente se modificaram para extensas corridas de detritos (GRAMANI, 2011). Provavelmente ainda existam resquícios deste grande processo, fato verificado pelas atividades de campo, o que corrobora a ocorrência de movimentos de massa do tipo debris flow nestas unidades fisiográficas com baixa densidade textural.

\section{Considerações finais}

Observou-se que as unidades fisiográficas localizadas na região serrana possuem maior potencialidade à ocorrência de processos de movimentos de massa devido aos seus valores de densidade textural (grande densidade de drenagem, grande densidade de relevo, altos valores de amplitudes locais e de declividade, forma de encostas que variam de convexa a retilínea e estruturas geológicas muito orientadas);

Ademais, as bacias hidrográficas do Rio Santo Antônio e do Córrego do Canivetal possuem maior potencialidade de geração desses processos, devido às suas características geológico-geotécnicas, tais como altas declividades e extensas encostas convexas-retilíneas. Futuramente, com a finalidade de determinar o raio de alcance de possíveis movimentos de massa no local, serão empregadas modelagens numéricas na área a partir de softwares de simulação 3D.

\section{Agradecimentos}

Os autores agradecem a Agência Nacional de Petróleo (ANP) pelo fomento à pesquisa e à bolsa de pesquisa concedida. O trabalho foi desenvolvido no âmbito do Programa de Formação de Recursos Humanos em Geologia e Ciências Ambientais aplicadas ao Petróleo da UNESP - PRH 05, com apoio do PRH/ANP.

\section{Bibliografia}

ALMEIDA, F. F. M. Fundamentos Geológicos do Relevo Paulista. Boletim do Instituto de Geografia e Geologia, São Paulo, n. 41, p. 169-263. 1964. 


\section{OS DESAFIOS DA GEOGRAFIA FÍSICA NA FRONTEIRA DO CONHECIMENTO \\ Instituto de Geociências - Unicamp \\ Campinas - SP \\ 28 de Junho à 02 de Julho de 2017}

AUGUSTO FILHO, O. Cartas de risco de escorregamentos: uma proposta metodológica e sua aplicação no município de Ilhabela, SP. Dissertação (Mestrado em Engenharia), Escola Politécnica, Universidade de São Paulo, São Paulo, 1992. 162 p.

BRUNSDEN, D.; PRIOR, D. B. Slope Instability. Chichester: John Wiley, 1984.

CARDOSO, D.; RIEDEL, P.S.; VEDOVELlO, R.; BROLlO, M.J.; TOMINAGA, L.K. Compartimentação fisiográfica do município de Peruíbe, litoral de São Paulo - uma abordagem metodológica como subsídio à avaliação geotécnica de terrenos. Pesquisas em Geociências, v.3, n. 36, p. 251-262, set./dez. 2009.

CORRÊA, C.V. S. Zoneamento Geoambiental da região compreendida pelas folhas topográficas São José dos Campos e Jacareí- SP. Dissertação (Mestrado em Geociências e Meio Ambiente), Instituto de Geociências e Ciências Exatas, UNESP - Universidade Estadual Paulista “Júlio de Mesquita Filho", 2013. 172 p.

CPRM - COMPANHIA DE PESQUISA DE RECURSOS MINERAIS. Mapa geológico da Folha Caraguatatuba. SF-23-Y-D-VI-1. São Paulo: CPRM, 1982. Escala 1:50.000.

CPRM - COMPANHIA DE PESQUISA DE RECURSOS MINERAIS. Mapa geológico da Folha Pico do Papagaio. SF-23-Y-D-V-2. São Paulo: CPRM, 1991. Escala 1:50.000.

EM-DAT. International Disaster Database. 2008. Disponível em: 〈www.emdat.be>. Acesso em: 02 mar. 2017.

FERNANDES, N. F.; AMARAL, C. P. Movimentos de massa: uma abordagem geológico-geomorfológica. In: Guerra, A.J.T.; Cunha, S.B. (Orgs.). Geomorfologia e Meio Ambiente. Rio de Janeiro: Bertrand, 1996. p. $123-194$.

FREITAS, C. G. L.; TAVEIRA, L. S.; PECCHIAI, F. Situações de risco na região da Serra do Mar no Estado de São Paulo: obras lineares. In: Simpósio Latino Americano sobre risco geológico urbano, 1, 1990, São Paulo. Anais... São Paulo: ABGE, 1990.

GOMES, R.A.T. Modelagem de Previsão de Movimentos de Massa a Partir da Combinação de Modelos de Escorregamentos e Corridas de Massa. Tese (Doutorado) - Geografia, UERJ, Rio de Janeiro, 2006. 180p.

GOMES, C.L.R.; OGURA, A.T.; GRAMANI, M.F.; CORSI, A.C.; ALAMEDDINE, N. Retro-análise da corrida de massa ocorrida no ano de 1967 nas encostas da Serra do Mar, vale dos rios Camburu, Pau D ${ }^{\text {ee }}$ Alho e Canivetal, município de Caraguatatuba - SP: quantificação volumétrica dos sedimentos depositados nas planícies de inundação. In: Congresso Brasileiro de Geologia de Engenharia e Ambiental, 12, Recife, 2008. Anais... Recife: ABGE, 2008. CD-ROM.

GRAMANI, M.F. Caracterização geológica-geotécnica das corridas de detritos ("Debris Flows") no Brasil e comparação com alguns casos internacionais. Dissertação (Mestrado em Engenharia de Solos), EPUSP - Escola Politécnica, Universidade de São Paulo, São Paulo. 2001. 372 p.

GUY, M. Quelques principes e quelques expériences surla methodologie de la photointerpretation. In: Symp. Intern. Photo-Interpretation, 2., Paris, Acte... v.1, p. 21-41. 1966.

IBGE - INSTITUTO BRASILEIRO DE GEOGRAFIA E ESTATÍSTICA. Folha de Maresias. São Paulo: IBGE, 1973. SF-23-Y-D-V-4. Escala 1:50.000

IBGE - INSTITUTO BRASILEIRO DE GEOGRAFIA E ESTATÍSTICA. Folha de Caraguatatuba. São Paulo: IBGE, 1974a. SF-23-Y-D-VI-1. Escala 1:50.000.

IBGE - INSTITUTO BRASILEIRO DE GEOGRAFIA E ESTATÍSTICA. Folha do Pico do Papagaio. São Paulo: IBGE, 1974b. SF-23-Y-D-V-2. Escala 1:50.000.

IBGE - INSTITUTO BRASILEIRO DE GEOGRAFIA E ESTATÍSTICA. Folha de São Sebastião. São Paulo: IBGE, 1975. SF-23-Y-D-VI-3. Escala 1:50.000.

IG - INSTITUTO GEOLÓGICO DO ESTADO DE SÃO PAULO. Mapa geológico do município de São Sebastião. São Paulo: IG, 1996. Escala 1:50.000.

IPT - INSTITUTO DE PESQUISAS TECNOLÓGICAS. Estudo das instabilizações de encostas na Serra do Mar na região de Cubatão objetivando a caracterização do fenômeno "corrida de lama" e da prevenção de seus efeitos. Relatório n. 26 258. 1988. 
LARSEN, M. C.; TORRES-SANCHEZ, A. J. The frequency and distribution of recent landslides in three montane tropical regions of Puerto Rico. Geomorphology, v. 24, p. 309- 331. 1998.

MONTGOMERY, D.R. Road surface drainage, channel initiation, and slope instability. Water Resources Research, v. 30, p. 1925-1932. 1994.

OLIVEIRA, E.M. Carta geológico-geotécnica como subsídio a elaboração de cartas de sensibilidade ambiental, a derrames de petróleo e derivados, na região do oleoduto "Guararema-São José dos Campos”, Vale do Paraíba (SP). Dissertação (Mestrado em Geociências e Meio Ambiente), Instituto de Geociências e Ciências Exatas, UNESP Universidade Estadual Paulista "Júlio de Mesquita Filho", 2009.

ONU - ORGANIZAÇÃO DAS NAÇÕES UNIDAS. Working party on world landslide inventory. Bulletin of the IAEG, 41, p. 5-12. 1993.

PAULA, J. P. L. de; ZAINE, J. E.; LIMA M. S.; OLIVEIRA, E. M. de. Análise fisiográfica aplicada à elaboração de mapa geológico-geotécnico da região da Serra do Mar e Baixada Santista. São Paulo: Revista Geociências, UNESP, 27 (2), p. 249-264, 2008.

PENIDO, L. R.; KUX, H. J. H.; MATTOS, J. T. Aplicação de Técnicas de Sensoriamento Remoto e GIS como subsídio ao planejamento rodoviário. Estudo de Caso: Trecho Oeste do Rodoanel Metropolitano de São Paulo, Brasil. In: Simpósio Brasileiro de Sensoriamento Remoto, 9., 1998, Santos. Anais... São Paulo: Imagem Multimídia. Seção de Comunicações Técnico-Científicas, 2003. CD-ROM.

SILVA, P. C. F.; VEDOVELLO, R.; FERREIRA, C. J.; CRIPPS,J. C.; BROLLO, M. J.; FERNANDES, A. J . Geoenvironmental mapping using physiographic analysis: constraints on the evaluation of land instability and groundwater pollution hazards in the Metropolitan District of Campinas, Brazil. Environmental Earth Sciences, v.61, n.8, p. 1657-1675, 2010.

SILVA-FILHO, E.P. Movimentos de massa na vertente sul florestada do maciço da Tijuca: casos de fevereiro/1988 nas estradas Dona Castorina e Vista Chinesa. Dissertação (Mestrado em Geografia), Universidade Federal do Rio de Janeiro, 1992.

SOARES, P. C.; FIORI, A. P. Lógica e sistemática na análise e interpretação de fotografias aéreas em geologia. Notícia Geomorfológica, v. 16, n. 32, p. 71-104, 1976.

SOARES, P.C.; FIORI, A.P.; MATTOS, J.T. A lógica de interpretação de fotografias aéreas convencionais aplicada a imagens de satélite. In: Simpósio Brasileiro de Sensoriamento Remoto, 1. São José dos Campos. Anais... São José dos Campos: CNPq/INPE. p. 616-618. 1978.

VEDOVELLO, R. Zoneamentos Geotécnicos Aplicados à Gestão Ambiental, a partir de Unidades Básicas de Compartimentação - UBCs. Tese (Doutorado em Geociências e Meio Ambiente), Instituto de Geociências e Ciências Exatas, Universidade Estadual Paulista "Júlio de Mesquita Filho", Rio Claro, 2000.

VENEZIANI, P; ANJOS, C. E. Metodologia de interpretação de dados de Sensoriamento Remoto e aplicações em Geologia. São José dos Campos: INPE, 1982. 54p.

WRIGHT, V. G.; KRONE, R. B. Erosion processes in upland areas. In: FRENCH, R.H. (ed.). Hydraulics/Hidrology of Arid Lands (H2AL). p.142-147. 1990.

ZAINE, J. E. Método de Fotogeologia aplicado a estudos geológico-geotécnicos: ensaio em Poços de Caldas, MG. Tese (Livre docência em Geociências e Meio Ambiente), Instituto de Geociências e Ciências Exatas, Universidade Estadual Paulista “Júlio de Mesquita Filho”, Rio Claro, 2011.

ZERKAL, S.V.; ZERKAL, O.V. Simulation flow landslides by particle method. In: International Symposium on landslides, 9, 2004. Rio de Janeiro. Anais... Rio de Janeiro: 2004. 